\title{
Ginkgolic acid and anacardic acid are specific covalent inhibitors of SARS-CoV-2 cysteine proteases
}

\author{
Zinuo Chen ${ }^{1 \dagger}{ }^{1}$, Qinghua Cui ${ }^{1,2,3 \dagger}$, Laura Cooper ${ }^{4 \dagger}$, Pin Zhang ${ }^{5}$, Hyun Lee ${ }^{6}$, Zhaoyu Chen ${ }^{1}$, Yanyan Wang , \\ Xiaoyun Liu ${ }^{2}$, Lijun Rong ${ }^{4^{*}}$ and Ruikun $\mathrm{Du}^{1,2,3^{*}}$ (])
}

\begin{abstract}
Background: In the urgent campaign to develop therapeutics against SARS-CoV-2, natural products have been an important source of new lead compounds.

Results: We herein identified two natural products, ginkgolic acid and anacardic acid, as inhibitors using a highthroughput screen targeting the SARS-CoV-2 papain-like protease $\left(\mathrm{PL}^{\mathrm{pro}}\right)$. Moreover, our study demonstrated that the two hit compounds are dual inhibitors targeting the SARS-CoV-2 3-chymotrypsin-like protease (3CL $\mathrm{L}^{\text {pro }}$ ) in addition to $P L^{\text {pro }}$. A mechanism of action study using enzyme kinetics further characterized the two compounds as irreversible inhibitors against both $3 \mathrm{CL}^{\text {pro }}$ and $\mathrm{PL}^{\text {pro }}$. Significantly, both identified compounds inhibit SARS-CoV-2 replication in vitro at nontoxic concentrations.
\end{abstract}

Conclusions: Our finding provides two novel natural products as promising SARS-CoV-2 antivirals.

Keywords: SARS-CoV-2, Natural product, Ginkgolic acid, Anacardic acid, Papain-like protease

\section{Background}

The pandemic of coronavirus disease 2019 (COVID-19), which is caused by the novel severe acute respiratory syndrome coronavirus-2 (SARS-CoV-2), has led to more than 93.81 million confirmed cases and approximately 2.03 million deaths globally (as of January 19, 2021, per the World Health Organization). Vaccines and antivirals are two major countermeasures to combat this viral infection. Encouraging progress has been achieved in vaccine developments, with several vaccine candidates either conditionally approved or in phase III clinical trials

\footnotetext{
*Correspondence: lijun@uic.edu; duzi857@163.com

†Zinuo Chen, Qinghua Cui and Laura Cooper contributed equally to this work

${ }^{1}$ College of Pharmacy, Shandong University of Traditional Chinese Medicine, Jinan 250355, China

${ }^{4}$ Department of Microbiology and Immunology, College of Medicine, University of Illinois at Chicago, Chicago, IL 60612, USA

Full list of author information is available at the end of the article
}

[1]. However, escape mutations might occur rapidly [2], and COVID-19 reinfection in the presence of neutralizing antibodies has been observed [3], these observations collectively may compromise the efficacy of vaccines. Regarding drug discovery and development, a repurposed drug remdesivir has been granted authorization by the Food and Drug Administration (FDA) of the United States; however, the efficacy of remdesivir in the treatment of COVID-19 patients is still under debate [4]. Discovery and development of more reliable with high efficacy antivirals are urgent.

SARS-CoV-2 is an enveloped, positive-stranded RNA virus, which belongs to the betacoronavirus genera. In infected cells, translation of the viral RNA initially produce 2 polyproteins, pp1a and pp1ab, which are subsequently cleaved by two viral cysteine proteases, the 3 -chymotrypsin-like protease $\left(3 \mathrm{CL}^{\mathrm{pro}}\right)$ and the papainlike protease $\left(\mathrm{PL}^{\mathrm{pro}}\right)$, yielding 16 mature nonstructural proteins [5]. Due to the critical roles of $3 \mathrm{CL}^{\text {pro }}$ and $\mathrm{PL}^{\text {pro }}$

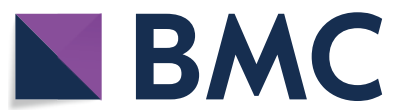

(c) The Author(s) 2021. This article is licensed under a Creative Commons Attribution 4.0 International License, which permits use, sharing, adaptation, distribution and reproduction in any medium or format, as long as you give appropriate credit to the original author(s) and the source, provide a link to the Creative Commons licence, and indicate if changes were made. The images or other third party material in this article are included in the article's Creative Commons licence, unless indicated otherwise in a credit line to the material. If material is not included in the article's Creative Commons licence and your intended use is not permitted by statutory regulation or exceeds the permitted use, you will need to obtain permission directly from the copyright holder. To view a copy of this licence, visit http://creativeco mmons.org/licenses/by/4.0/. The Creative Commons Public Domain Dedication waiver (http://creativecommons.org/publicdomain/ zero/1.0/) applies to the data made available in this article, unless otherwise stated in a credit line to the data. 
during viral polyprotein processing, both $3 \mathrm{CL}^{\mathrm{pro}}$ and $\mathrm{PL}^{\text {pro }}$ have been well acknowledged as attractive antiviral drug targets. Up to now, numerous inhibitors directed at $3 \mathrm{CL}^{\text {pro }}$ have been reported, providing valuable lead compounds for further development [6, 7]. Although there have been less inhibitor-development studies directed at $\mathrm{PL}^{\text {pro }}$, the structural and functional studies have proven the essential roles of $\mathrm{PL}^{\text {pro }}$ in viral infection and replication [8]. Beyond viral polyprotein processing, $\mathrm{PL}^{\mathrm{pro}}$ is also involved in the regulation of innate immune response, by removal of ubiquitin (Ub) and Ub-like protein ISG15 (interferon-induced gene 15) from cellular proteins [9]. A $\mathrm{PL}^{\text {pro }}$ inhibitor may therefore act in a dual therapeutic manner by both suppressing SARS-CoV-2 replication and promoting antiviral immunity.

We herein optimized a sensitive fluorescence-based high-throughput screen approach to discover SARSCoV-2 PL pro inhibitors. A library consisting of 1920 natural products was subsequently screened and two compounds ginkgolic acid and anacardic acid were identified to have antiviral potency against SARS-CoV-2.

\section{Results}

Establishing the fluorescence-based enzymatic assay for the SARS-CoV-2 PL ${ }^{\text {pro }}$

The codon optimized PL ${ }^{\text {pro }}$ gene of SARS-CoV-2 was cloned into pET32a $(+)$ vector and expressed in BL21 (DE3) Escherichia coli. with Trix-His-S tags fusing to the N-terminus. The $\mathrm{PL}^{\text {pro }}$ protein was purified with Ni-NTA column to high purity, and the redundant tags were removed by EK digestion prior to activity assays (Fig. 1a). To establish the in vitro enzymatic assay of SARS-CoV-2 PL pro, a substrate containing the five C-terminal residues of human ubiquitin with a C-terminal 7-amido-4-methylcoumarin (AMC) group, Z-RLRGG-AMC, was used as previously described [10]. Hydrolysis of the AMC-peptide bond by PL ${ }^{\text {pro }}$ can dramatically increase the fluorescence of the AMC moiety. To better characterize the enzymatic property, the $\mathrm{Km}$ value of SARS-CoV-2 $\mathrm{PL}^{\text {pro }}$ was measured. Upon mixture of $100 \mathrm{nM} \mathrm{PL}^{\text {pro }}$ with various concentrations of fluorometric substrate $(0-2 \mathrm{mM})$, the initial velocity $\left(\mathrm{V}_{0}\right)$ was measured and plotted to substrate concentration. Curve fitting with Michaelis-Menten equation gave the best-fit $\mathrm{Km}$ value of $70.92 \pm 10.15 \mu \mathrm{M}$ (Fig. 1b).

\section{Screen of a natural product library against SARS-CoV-2 PL pro}

The SARS-CoV-2 PL pro enzymatic assay was next adapted for a high-throughput screening approach, and a library consisting of 1920 natural products was screened to identify potential SARS-CoV-2 inhibitors. The compounds were pre-incubated with $100 \mathrm{nM}$ of $\mathrm{PL}^{\text {pro }}$ at room temperature for $30 \mathrm{~min}$ in reaction buffer containing $4 \mathrm{mM}$ dithiothreitol (DTT) before the addition of $30 \mu \mathrm{M}$ fluorometric substrate. All compounds were tested at $20 \mu \mathrm{M}$. As shown in Fig. 2a, five compounds showed more than $50 \%$ inhibition against $\mathrm{PL}^{\text {pro }}$. Among these hits (Fig. 2b, c), tannic acid, methylcobalamin, and theaflavin 3,3'-digallate have been proposed as potent SARS-CoV-2 inhibitors in previous studies [11-13], while ginkgolic acid and anacardic acid were identified for the first time so far to our knowledge. We therefore focused on these two hits for further analysis.
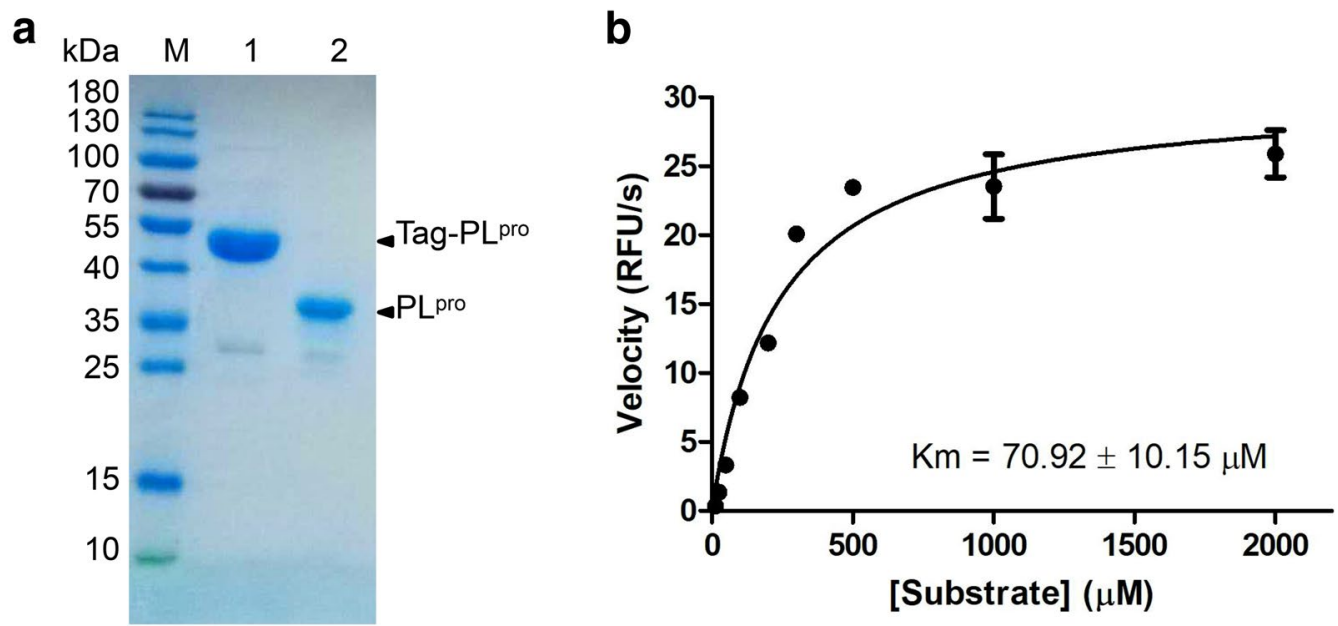

Fig. 1 SARS-CoV-2 PL pro expression and characterization. a SDS-PAGE of purified PL ${ }^{\text {pro }}$. Lane M: protein ladder; lane 1: tagged-PL pro; lane 2: authentic $\mathrm{PL}^{\text {pro }}$. b Michaelis-Menten plot of $100 \mathrm{nM} \mathrm{PL}{ }^{\text {pro }}$ with various concentrations of fluorometric substrate. The best-fit Km $=70.92 \pm 10.15 \mu \mathrm{M}$ 

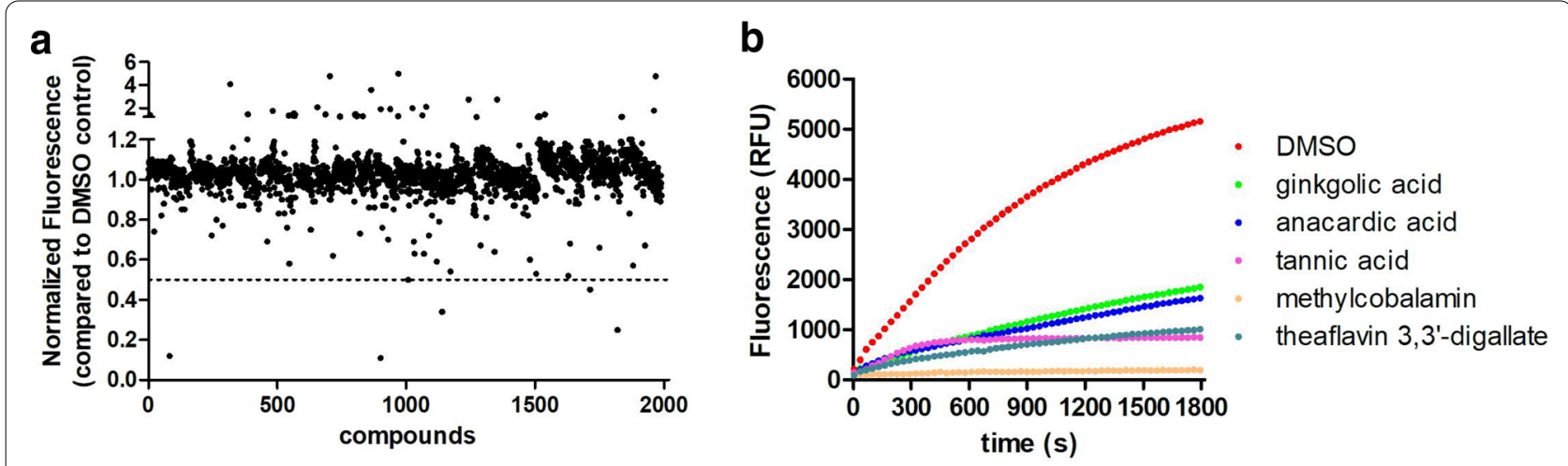

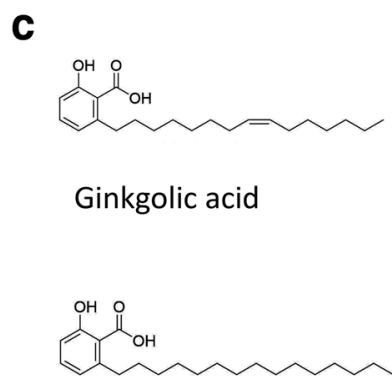

Anacardic acid

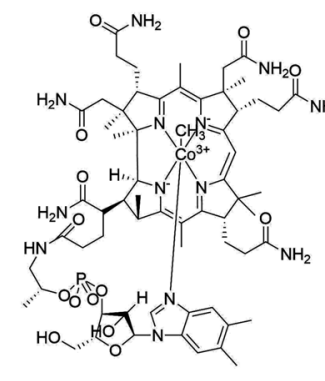

Methylcobalamin

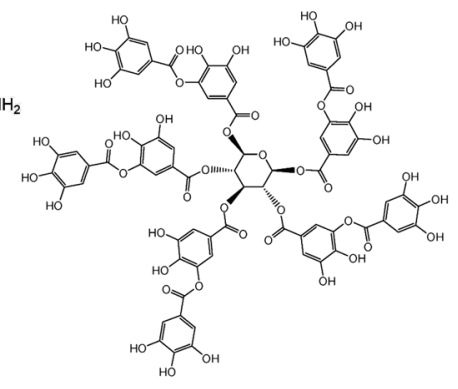

Tannic acid

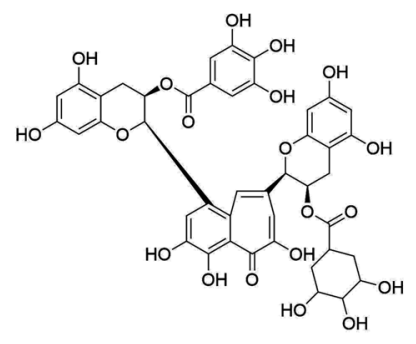

Theaflavin 3,3'-digallate

Fig. 2 High-throughput screening of a library of natural products against PL pro identifies 5 hit inhibitors. a Results from screening of 1920 natural products for inhibition of PL ${ }^{\text {pro }}$ activity. The relative fluorescence units (RFUs) at $10 \mathrm{~min}$ after reaction initiation were normalized to DMSO control and used to indicate the enzymatic activities. The dashed line indicates the threshold for hit selection ( $>50 \%$ fluorescence reduction). $\mathbf{b}$ The original reaction progression curves in presence of DMSO or hit compounds. $\mathbf{c}$ The structures of the hit compounds

\section{Ginkgolic acid and anacardic acid are dual inhibitors targeting both $\mathrm{PL}^{\text {pro }}$ and $3 \mathrm{CL}^{\text {pro }}$ of SARS-CoV-2}

To validate ginkgolic acid and anacardic acid as PL ${ }^{\text {pro }}$ inhibitors, dose response analysis was conducted using an enzymatic inhibition assay. As a result, both ginkgolic acid and anacardic acid dose-dependently inhibited $\mathrm{PL}^{\text {pro }}$ activity, with $\mathrm{IC}_{50}$ values of $16.30 \pm 0.64$ and $17.08 \pm 1.30 \mu \mathrm{M}$, respectively (Fig. 3a). Furthermore, neither ginkgolic acid nor anacardic acid interferes with fluorescence detection at tested concentrations (Additional file 1: Figure S1). These results clearly demonstrated ginkgolic acid and anacardic acid as SARS-CoV-2 PL ${ }^{\text {pro }}$ inhibitors.

Interestingly, in a parallel screen against SARSCoV-2 $3 \mathrm{CL}^{\text {pro }}$, ginkgolic acid and anacardic acid were also identified as inhibitors of $3 \mathrm{CL}^{\text {pro }}$, with $\mathrm{IC}_{50}$ values of $1.79 \pm 0.58$ and $2.07 \pm 0.35 \mu \mathrm{M}$, respectively (Fig. 3b). Compared to PLpro, 3CLpro is about 10 times sensitive to both ginkgolic acid and anacardic acid. These data suggest that ginkgolic acid and anacardic acid are dual inhibitors against both SARS-CoV-2 $3 C L^{\text {pro }}$ and $P L^{\text {pro }}$.

\section{Ginkgolic acid and anacardic acid exhibit antiviral activity in vitro}

To evaluate the antiviral potency of ginkgolic acid and anacardic acid, the two hit inhibitors were subsequently tested against authentic SARS-CoV-2 in vitro. A cytotoxicity assay was performed firstly to determine nontoxic concentrations of ginkgolic acid and anacardic acid. As Fig. 4a shows, the $\mathrm{CC}_{50}$ values of ginkgolic acid and anacardic acid to Vero-E6 cells are 27.88 \pm 0.77 and $25.48 \pm 0.69 \mu \mathrm{M}$, respectively. No obvious toxicity (>90\% cell viability) was observed at $20 \mu \mathrm{M}$ for both ginkgolic acid and anacardic acid.

When subjected to a viral plaque reduction assay with authentic SARS-CoV-2, both ginkgolic acid and anacardic acid significantly reduced virus plaque formation at a concentration of $15 \mu \mathrm{M}$ (Fig. 4b), suggesting that the two hit inhibitors can block SARS-CoV-2 replication at non-toxic concentrations. Of note, ginkgolic acid showed $42 \%$ inhibition at $7.5 \mu \mathrm{M}$ with estimated $\mathrm{EC}_{50}$ value of $8.3 \pm 0.03 \mu \mathrm{M}$ compared to $13 \%$ inhibition at $7.5 \mu \mathrm{M}$ with estimated $\mathrm{EC}_{50}$ value of $9.0 \pm 2.5 \mu \mathrm{M}$ for anacardic acid, indicating a higher antiviral potency (Fig. 4b). 

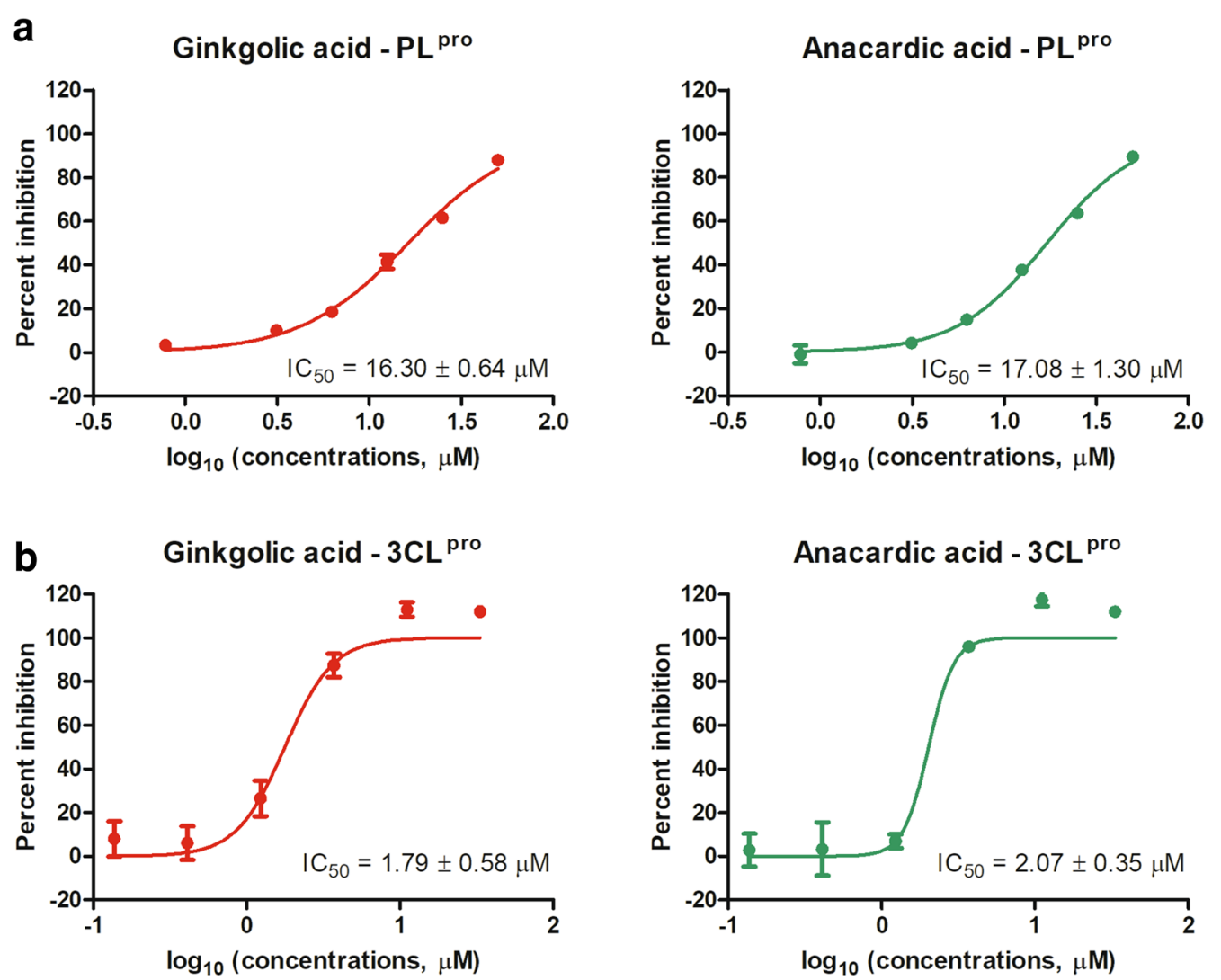

Fig. $3 \mathrm{PL} \mathrm{L}^{\text {pro }}$ and $3 \mathrm{CL}^{\text {pro }}$ enzymatic inhibition assay. The $\mathrm{IC}_{50}$ curves of ginkgolic acid and anacardic acid against enzymatic activities of $\mathrm{PL}^{\text {pro }}(\mathbf{a})$ and $3 \mathrm{CL}^{\text {pro }}(\mathbf{b})$ were indicated. For each compound, the $\mathrm{IC}_{50}$ value is displayed in the bottom right corner. The data represent mean \pm standard deviation (SD) of the triplicate measurements

\section{Ginkgolic acid is an irreversible inhibitor against $3 \mathrm{CL}^{\text {pro }}$ and $\mathrm{PL}^{\text {pro }}$}

Given the high structural similarity of ginkgolic acid and anacardic acid, we focused on ginkgolic acid to further elucidate its mechanism of action. The proteolytic activity of the $3 \mathrm{CL}^{\text {pro }}$ was firstly measured using a series of enzyme concentrations and at various inhibitor concentrations. The substrate concentrations were held constant at sub-saturation levels. At each concentration of ginkgolic acid, the initial reaction velocities were plotted with the concentrations of $3 \mathrm{CL}^{\text {pro }}$, and the data was fitted using linear regression analysis. As shown in Fig. 5a, as the concentration of ginkgolic acid increases, the best-fit line shifts to right, without altering the slope significantly. Similar results were obtained for ginkgolic acid against $\mathrm{PL}^{\text {pro }}$ (Fig. 5b). This phenomenon clearly implies that ginkgolic acid act as an irreversible inhibitor against both SARS-CoV-2 cysteine proteases.

\section{In silico docking}

To better deduce the binding modes involved in the interaction of ginkgolic acid with SARS-CoV-2 cysteine proteases, an in silico docking study was performed using AutoDock Vina software. As a result, the substrate binding pockets of both $3 \mathrm{CL}^{\text {pro }}$ and $\mathrm{PL}^{\text {pro }}$ can be occupied by ginkgolic acid, with predicted affinity of -5.3 and $-4.9 \mathrm{kcal} / \mathrm{mol}$ respectively. The binding mode of ginkgolic acid to $3 \mathrm{CL}^{\text {pro }}$ is described in Fig. 6a. Among the four sites ( $\mathrm{S}^{\prime}, \mathrm{S} 1, \mathrm{~S} 2$ and $\left.\mathrm{S} 4\right)$ within the highly conserved active cavity of $3 \mathrm{CL}^{\text {pro }}$, ginkgolic acid mainly targets to S1 and S4 [6]. On the other hand, as depicted in Fig. 6b, ginkgolic acid accommodates in the substrate cleft formed between the BL2 loop and the $\alpha 3-\alpha 4$ loop of $\mathrm{PL}^{\mathrm{pro}}$, which is almost identical to the mode of GRL-0617 [8].

\section{Discussion}

The development of cysteine protease inhibitors is usually plagued with either notable toxicities or lack of specificity due to covalent modification of untargeted cysteine residues [10]. It was argued that the scientific community should be aware of these nonspecific effects, which could be ruled out by addition of reducing reagents in the enzymatic buffer [14]. In the present study, we identified 

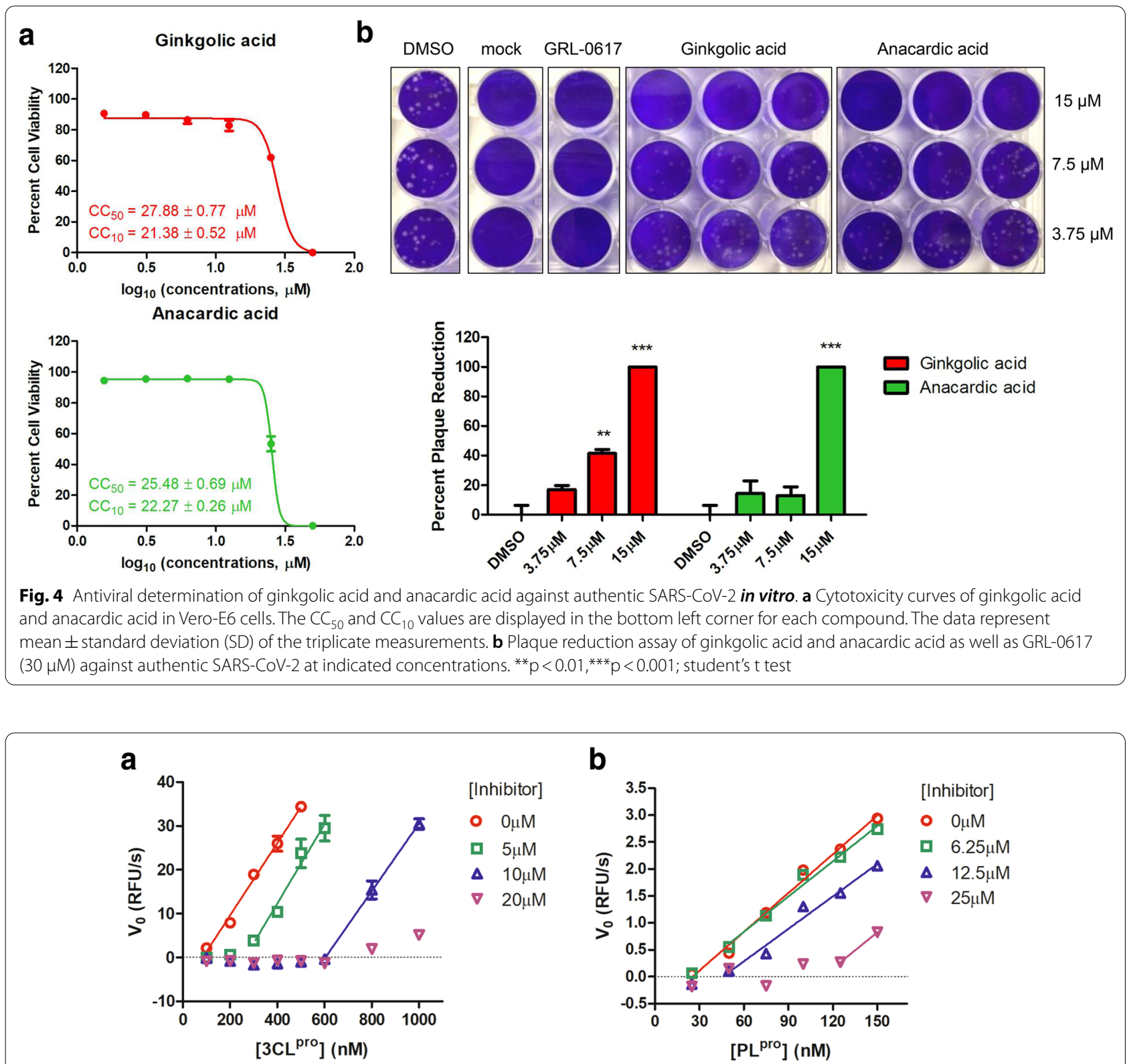

Fig. 5 Graphical determination of the type of enzymatic inhibition. Relationship of the enzymatic activity of SARS-CoV-2 $3 C^{\text {pro }}$ (a) and PL ${ }^{\text {pro }}(\mathbf{b})$ as function of enzyme concentrations at different concentrations of ginkgolic acid

ginkgolic acid and anacardic acid as novel SARS-CoV-2 cysteine protease inhibitors. Upon addition of reducing reagent in the $3 \mathrm{CL}^{\text {pro }}$ enzymatic assay, no significant $\mathrm{IC}_{50}$ shift was observed (Additional file 2: Figure S2), suggesting the specificity of ginkgolic acid and anacardic acid as cysteine protease inhibitors [14].

Given the fact that ginkgolic acid and anacardic acid inhibit both $3 \mathrm{CL}^{\text {pro }}$ and PL ${ }^{\text {pro }}$ of SARS-CoV-2, one may be concerned that the two inhibitors are potent broadly cysteine protease inhibitors [15]. Although this usually means the compounds are toxic to host cells by targeting cellular cysteine proteases, our study demonstrated the antiviral activities of ginkgolic acid and anacardic acid against authentic SARS-CoV-2 at non-toxic concentrations, suggesting the two compounds deserve further development as novel potential COVID-19 therapies.

Based on our studies, ginkgolic acid act as an irrivesible inhibitor against both $\mathrm{PL}^{\text {pro }}$ and $3 \mathrm{CL}^{\mathrm{pro}}$, suggesting it a covalent inhibitor. As described above, the specificity is critical during development of a covalent cysteine 

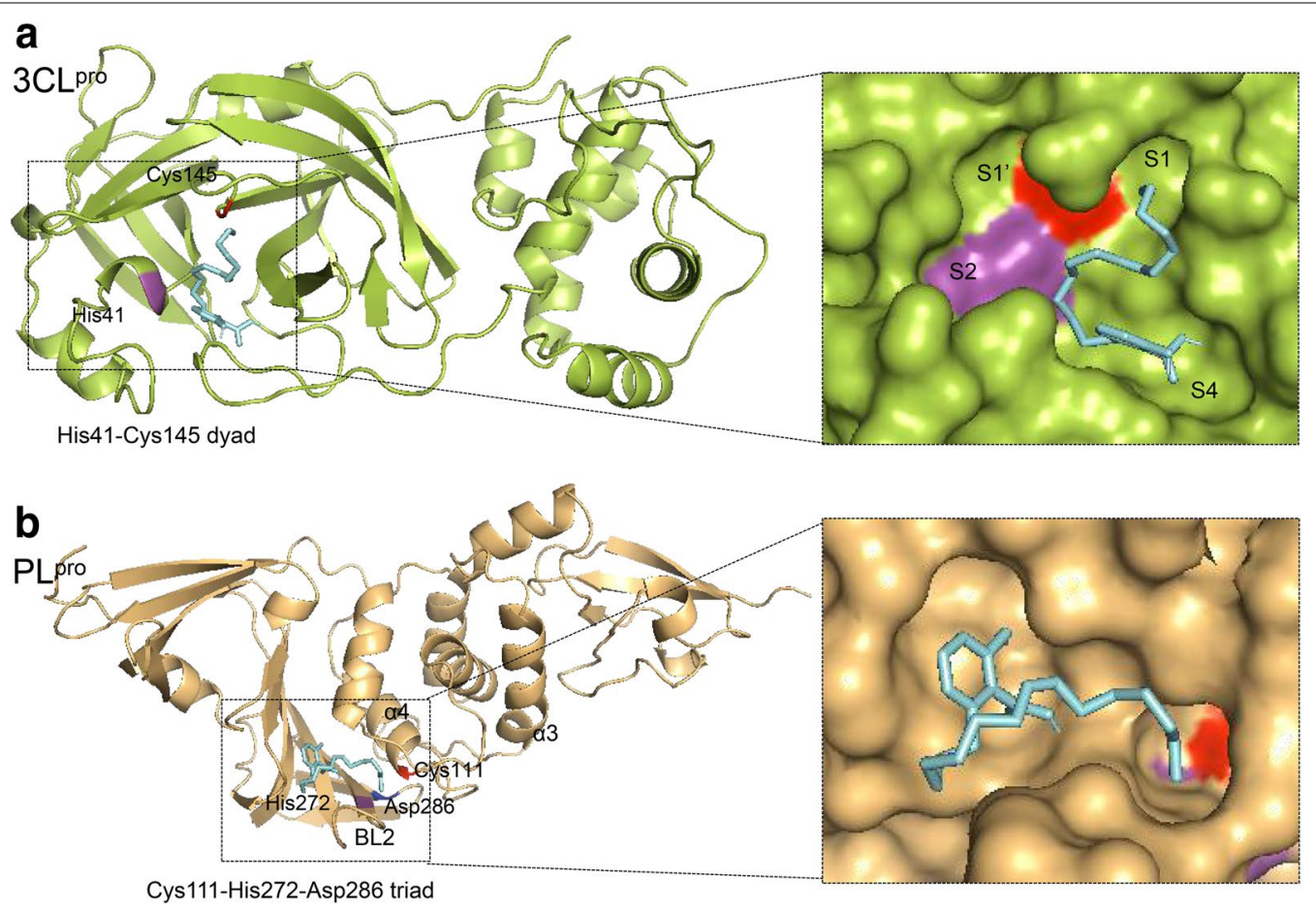

Fig. 6 Predicted binding modes of ginkgolic acid to SARS-CoV-2 3CL pro (a) and PL ${ }^{\text {pro }}$ (b). The 3CL ${ }^{\text {pro }}$ (PDB ID: 6m2n) and PL ${ }^{\text {pro }}$ (PDB code: 6WX4) are shown in green and orange cartoon respectively. The ginkgolic acid is shown in cyan sticks. The enlarged views represent ginkgolic acid in the active site with a view of the molecular surface of SARS-CoV-2 3CL ${ }^{\text {pro }}(\mathbf{a})$ and PL ${ }^{\text {pro }}(\mathbf{b})$. The His41-Cys145 dyad of 3CL ${ }^{\text {pro }}$ and Cys 111-His272-Asp286 triad of PL pro were indicated

protease inhibitor, which could be achieved by rational design. A two-step mechanism of action is usually adopted by those specific covalent inhibitors, such as peptidic inhibitors of SARS-CoV $3 \mathrm{CL}^{\text {pro }}, \mathrm{N} 3$ and GC376 $[7,16]$. First, the inhibitor may competitively bind to the substrate binding cavity of SARS-CoV-2 cysteine proteases, bringing a warhead to a close proximity to catalytic cysteine. Second, a covalent bond would form at slower velocity between the inhibitor and target cysteine, conferring an irreversible inhibition. We speculate ginkgolic acid and anacardic acid act in the similar two-step mechanism of action as specific covalent inhibitors.

\section{Conclusions}

We herein report ginkgolic acid and anacardic acid as two novel SARS-CoV-2 inhibitors dually targeting $3 \mathrm{CL}^{\text {pro }}$ and $\mathrm{PL}^{\text {pro }}$. These two inhibitors are valuable to be developed as a new class of specific covalent cysteine protease inhibitors.

\section{Methods}

\section{Reagents and viruses}

The library containing 1920 natural products was purchased from MedChemExpress (MCE; Monmouth Junction, NJ, USA). The clinical isolate of SARS-CoV-2
(SARS-CoV-2, Isolate USA-WA1/2020) was obtained from BEI Resources and manipulated in BSL3 containment at University of Illinois at Chicago (Chicago, IL).

\section{Expression and purification of SARS-CoV-2 PL pro from Escherichia coli}

The $\mathrm{PL}^{\text {pro }}$ gene was amplified from the codon-optimized nsp3 template (kindly gifted by Dr. Shengce Tao from Shanghai Jiaotong University) using primers PL ${ }^{\text {pro }}$-forward: 5 '-GGCCGGATCCGGTCACCGGTT TAATGGTGGTG- $3^{\prime}$ and PL ${ }^{\text {pro }}$-reverse: $5^{\prime}$-GGCCAA GCTCTATCGTGAGGTTCGTACCATCAAG- $3^{\prime}$, and cloned into the pET-32a $(+)$ expression vector followed by transformation into BL21 (DE3) competent cells. The expression plasmid was constructed such that $\mathrm{PL}^{\text {pro }}$ carried N-terminal Trix-His6-S tag followed by an enterokinase cleavage site. Correct clones were verified by DNA sequencing. The protein expression was performed as previously described [17].

The purification of recombinant $\mathrm{PL}^{\text {pro }}$ was carried out using the BeyoGold His-tag protein purification kit (Beyotime, Shanghai, China) according to manufacturer's manual. The $\mathrm{N}$-terminal tags were removed by recombinant EK digestion prior to enzymatic assay. 


\section{Enzymatic assay of SARS-CoV-2 PL ${ }^{\text {pro }}$}

A fluorometric peptide Z-Arg-Leu-Arg-Gly-Gly-AMC (Z-RLRGG-AMC) was purchased from NJpeptide and used as substrate in $\mathrm{PL}^{\text {pro }}$ enzymatic assay as described previously [10]. Upon cleavage by $\mathrm{PL}^{\mathrm{pro}}$, the fluorescence of the AMC moiety dramatically increases, accurately reflecting the conversion. For $\mathrm{PL}^{\mathrm{pro}}$ inhibition assay, varying concentrations of inhibitor were mixed with $100 \mathrm{nM} \mathrm{PL}^{\text {pro }}$ in $90 \mu \mathrm{L}$ reaction buffer, containing $20 \mathrm{mM}$ Tris-buffer ( $\mathrm{pH}$ 8.0) and $4 \mathrm{mM}$ DTT, and incubated for $30 \mathrm{~min}$. Reactions were initiated by adding $10 \mu \mathrm{L}$ Z-RLRGG-AMC with a final concentration of $30 \mu \mathrm{M}$. The fluorescence signal was immediately measured every $30 \mathrm{~s}$ for $60 \mathrm{~min}$ using a Bio-Tek Synergy LX plate reader with filters for excitation at $360 / 20 \mathrm{~nm}$ and emission at $460 / 20 \mathrm{~nm}$. The initial reaction velocities $\left(V_{0}\right)$ of reactions were calculated to indicate the enzymatic activities. Three independent experiments were performed and $\mathrm{IC}_{50}$ curves were analyzed using fourparameter logistic regression in GraphPad Prism software. Note that the relative fluorescence units (RFUs) at $10 \mathrm{~min}$ after reaction initiation were used to indicate the enzymatic activities for high-throughput screen.

For mechanism of action study, various concentrations of ginkgolic acid were mixed and incubated with increasing concentrations of $\mathrm{PL}^{\text {pro }}(25-150 \mathrm{nM})$ in 90 $\mu \mathrm{L}$ reaction buffer for $30 \mathrm{~min}$. Reactions were initiated by adding $10 \mu \mathrm{L}$ substrate with a final concentration of $30 \mu \mathrm{M}$. At each concentration of ginkgolic acid, the $\mathrm{V}_{0} \mathrm{~s}$ were plotted with the concentrations of $\mathrm{PL}^{\text {pro }}$, and the data was fitted using linear regression analysis in GraphPad Prism software.

\section{Enzymatic assay of SARS-CoV-2 $3 \mathrm{CL}^{\text {pro }}$}

The SARS-CoV-2 $3 \mathrm{CL}^{\text {pro }}$ was prokaryotic expressed and purified as previously described with slight modification [7]. For enzymatic inhibition assay, the recombinant $3 \mathrm{CL}^{\text {pro }}(250 \mathrm{nM}$ at a final concentration) was incubated with increasing concentrations of each compound in $90 \mu \mathrm{L}$ reaction buffer $(50 \mathrm{mM}$ Tris $-\mathrm{HCl}, \mathrm{pH}$ 7.3, $1 \mathrm{mM}$ EDTA, 4mM DTT) for $30 \mathrm{~min}$ [6]. The reaction was initiated by adding $10 \mu \mathrm{L}$ FRET-based peptidic substrate (Dabcyl-KTSAVLQ/SGFRKME-Edans) with a final concentration of $50 \mu \mathrm{M}$. The fluorescence signal was immediately measured every $20 \mathrm{~s}$ for 30 min using a Bio-Tek Synergy4 plate reader with filters for excitation at $336 / 20 \mathrm{~nm}$ and emission at $490 / 20$ $\mathrm{nm}$. The $\mathrm{V}_{0}$ of reactions were calculated to indicate the enzymatic activities. Three independent experiments were performed and $\mathrm{IC}_{50}$ curves were analyzed using four-parameter logistic regression in GraphPad Prism software.
For mechanism of action study, various concentrations of ginkgolic acid were mixed and incubated with increasing concentrations of $3 \mathrm{CL}^{\text {pro }}(100-1000 \mathrm{nM})$ in $90 \mu \mathrm{L}$ reaction buffer for $30 \mathrm{~min}$. Reactions were initiated by adding $10 \mu \mathrm{L}$ substrate with a final concentration of 50 $\mu \mathrm{M}$. At each concentration of ginkgolic acid, the $\mathrm{V}_{0} \mathrm{~s}$ were plotted with the concentrations of $3 \mathrm{CL}^{\text {pro }}$, and the data was fitted using linear regression analysis in GraphPad Prism software.

\section{Antiviral determination}

To examine the antiviral activity against authentic SARSCoV-2 (Isolate USA-WA1/2020, from BEI Resources), a plaque reduction assay was conducted. Briefly, VeroE6 monolayers grown in 12 well plates were pre-treated with various concentrations of test compound for $1 \mathrm{~h}$, followed by infection with SARS-CoV-2 (MOI of 0.0001) in the presence of test compounds. DMSO and a known PL $^{\text {pro }}$ inhibitor GRL-0617 $(30 \mu \mathrm{M})$ were used as negative and positive controls respectively. After 1-h incubation, the medium was replaced with fresh MEM containing $1.25 \%$ Avicel and the test compounds, and the plates were incubated for another $48 \mathrm{~h}$ at $37{ }^{\circ} \mathrm{C}$ and $5 \% \mathrm{CO}_{2}$. Then cells were fixed with $10 \%$ formalin and stained with $1 \%$ crystal violet to visualize plaques. Three independent experiments were performed, and all data was normalized to virus alone. All experiments were performed in a Biosafety level 3 facility.

\section{Cytotoxicity assay}

To estimate the cytotoxicity of test compounds on VERO-E6 cells, Cell-Titer Glo ${ }^{\circledR}$ luminescent cell viability assay (Promega) was performed according to the manufacturer's instruction. Briefly, the drugs were 2 -fold serially diluted starting at $50 \mu \mathrm{M}$ in phenol red free DMEM and were incubated with cells for $48 \mathrm{~h}$ at $37{ }^{\circ} \mathrm{C}$ and $5 \%$ $\mathrm{CO}_{2}$. The half of the cytotoxic concentration $\left(\mathrm{CC}_{50}\right)$ values were calculated from the percentages of cells whose viability was inhibited by test compounds at various concentrations.

\section{In silico docking}

For the molecular docking simulations, the structures of $3 \mathrm{CL}^{\text {pro }}$ (PDB code: $6 \mathrm{~m} 2 \mathrm{n}$ ) and PLpro (PDB code: 6WX4) from SARS-CoV-2 were used. Before docking, polar hydrogen atoms were added to the target protein using autodock tools. Docking was performed using a grid box covering the entire structure by AutoDock Vina software [18]. After docking, the conformation of the compound was analyzed, and the $3 \mathrm{D}$ models were viewed with PyMOL. 


\section{Supplementary Information}

The online version contains supplementary material available at https://doi. org/10.1186/s13578-021-00564-x.

Additional file 1: Figure S1. Ginkgolic acid and anacardic acid don't interfere with fluorescence detection. Additional file 2: Figure S2. The $\mathrm{IC}_{50}$ Curves of ginkgolic acid and anacardic acid against enzymatic activities of $3 \mathrm{CL}^{\text {pro }}$ in absence or presence of $4 \mathrm{mM}$ DTT.

\section{Abbreviations}

COVID-19: Coronavirus disease 2019; SARS-CoV-2: Severe acute respiratory syndrome coronavirus-2; 3CL ${ }^{\text {pro: }}$ 3-Chymotrypsin-like protease; $P L^{\text {pro. }}$ Papain-like protease; Ub: Ubiquitin; AMC: 7-Amido-4-methylcoumarin; DTT: Dithiothreitol; RFU: Relative fluorescence units.

\section{Acknowledgements}

We thank Dr. Shengce Tao from Shanghai Jiaotong University for kindly providing the plasmid carrying codon-optimized nsp3 gene of SARS-CoV-2.

\section{Authors' contributions}

$R D, Q C, L C$ and $L R$ conceived and designed the experiments. ZC and LC, ZC, $P Z, X L$ and $R D$ performed the experiments. $Y W$ conducted the in silico docking. RD wrote the manuscript. LC, QC, PZ, HL and LR revised the manuscript. All authors reviewed the results. All authors read and approved the final manuscript.

\section{Funding}

This work was supported by grants from the Key Technology Research and Development Program of Shandong, China (2020CXGC010505) and Natural Science Foundation of Shandong Province, China (ZR2020MH383).

\section{Availability of data and materials}

All data generated or analyzed during this study are included in this article.

\section{Ethics approval and consent to participate}

Not applicable

\section{Consent for publication}

All authors approved for publication.

\section{Competing interests}

The authors declare no competing interests.

\begin{abstract}
Author details
${ }^{1}$ College of Pharmacy, Shandong University of Traditional Chinese Medicine, Jinan 250355, China. ${ }^{2}$ Experimental Center, Shandong University of Traditional Chinese Medicine, Jinan 250355, China. ${ }^{3}$ Qingdao Academy of Chinese Medicinal Sciences, Shandong University of Traditional Chinese Medicine, Qingdao 266122, China. ${ }^{4}$ Department of Microbiology and Immunology, College of Medicine, University of Illinois at Chicago, Chicago, IL 60612, USA.

${ }^{5}$ Chicago BioSolutions Inc, 2242 W Harrison Street, Chicago, Illinois 60612, United States. ${ }^{6}$ Department of Pharmaceutical Sciences, Center for Biomolecular Sciences, College of Pharmacy, Biophysics Core at Research Resources
\end{abstract} Center, University of Illinois at Chicago, Chicago, IL 60607, USA.

Received: 28 January 2021 Accepted: 21 February 2021 Published online: 28 February 2021

\section{References}

1. Dai L, Gao GF. Viral targets for vaccines against COVID-19. Nat Rev Immunol 2020;21:1-10.
2. Liu Z, VanBlargan LA, Rothlauf PW, Bloyet LM, Chen RE, Stumpf S, Zhao H, Errico JM, Theel ES, Ellebedy AH, et al: Landscape analysis of escape variants identifies SARS-CoV-2 spike mutations that attenuate monoclonal and serum antibody neutralization. bioRxiv 2020. doi: 10.1101/2020.11.06.372037

3. Zhang J, Ding N, Ren L, Song R, Chen D, Zhao X, Chen B, Han J, Li J, Song $Y$, et al: COVID-19 reinfection in the presence of neutralizing antibodies. National Science Review 2021.

4. Beigel JH, Tomashek KM, Dodd LE, Mehta AK, Zingman BS, Kalil AC, Hohmann E, Chu HY, Luetkemeyer A, Kline S, et al. Remdesivir for the treatment of Covid-19-final eeport. N Engl J Med. 2020;383(19):1813-26.

5. Hu B, Guo H, Zhou P, Shi ZL. Characteristics of SARS-CoV-2 and COVID-19. Nat Rev Microbiol 2020;19:1-14.

6. Dai W, Zhang B, Jiang XM, Su H, Li J, Zhao Y, Xie X, Jin Z, Peng J, Liu F, et al. Structure-based design of antiviral drug candidates targeting the SARSCoV-2 main protease. Science. 2020;368(6497):1331-5.

7. Ma C, Sacco MD, Hurst B, Townsend JA, Hu Y, Szeto T, Zhang X, Tarbet B, Marty MT, Chen Y, et al. Boceprevir, GC-376, and calpain inhibitors II, XII inhibit SARS-CoV-2 viral replication by targeting the viral main protease. Cell Res. 2020;30(8):678-92.

8. Gao X, Qin B, Chen P, Zhu K, Hou P, Wojdyla JA, Wang M, Cui S. Crystal structure of SARS-CoV-2 papain-like protease. Acta Pharm Sin B 2020;11:237.

9. Shin D, Mukherjee R, Grewe D, Bojkova D, Baek K, Bhattacharya A, Schulz L, Widera M, Mehdipour AR, Tascher G, et al. Papain-like protease regulates SARS-CoV-2 viral spread and innate immunity. Nature. 2020;587(7835):657-62.

10. Ratia K, Pegan S, Takayama J, Sleeman K, Coughlin M, Baliji S, Chaudhuri R, Fu W, Prabhakar BS, Johnson ME, et al. A noncovalent class of papain-like protease/deubiquitinase inhibitors blocks SARS virus replication. Proc Natl Acad Sci U S A. 2008;105(42):16119-24.

11. Wang SC, Chen Y, Wang YC, Wang WJ, Yang CS, Tsai CL, Hou MH, Chen HF, Shen YC, Hung MC. Tannic acid suppresses SARS-CoV-2 as a dual inhibitor of the viral main protease and the cellular TMPRSS2 protease. Am J Cancer Res. 2020;10(12):4538-46.

12. Chen CN, Lin CP, Huang KK, Chen WC, Hsieh HP, Liang PH, Hsu JT. Inhibition of SARS-CoV 3 C-like protease activity by theaflavin-3,3'-digallate (TF3). Evid Based Complement Alternat Med. 2005;2(2):209-15.

13. Narayanan N, Nair DT. Vitamin B12 may inhibit RNA-dependent-RNA polymerase activity of nsp 12 from the SARS-CoV-2 virus. IUBMB Life. 2020;72(10):2112-20.

14. Ma C, Hu Y, Townsend JA, Lagarias Pl, Marty MT, Kolocouris A, Wang J. Ebselen, Disulfiram, Carmofur, PX-12, Tideglusib, and Shikonin are nonspecific promiscuous SARS-CoV-2 main protease inhibitors. ACS Pharmacol Transl Sci. 2020;3(6):1265-77.

15. Lee H, Mittal A, Patel K, Gatuz JL, Truong L, Torres J, Mulhearn DC, Johnson ME. Identification of novel drug scaffolds for inhibition of SARS-CoV 3-Chymotrypsin-like protease using virtual and high-throughput screenings. Bioorg Med Chem. 2014;22(1):167-77.

16. Xue X, Yu H, Yang H, Xue F, Wu Z, Shen W, Li J, Zhou Z, Ding Y, Zhao Q, et al. Structures of two coronavirus main proteases: implications for substrate binding and antiviral drug design. J Virol. 2008;82(5):2515-27.

17. Song YH, Kim DW, Curtis-Long MJ, Yuk HJ, Wang Y, Zhuang N, Lee KH, Jeon KS, Park KH. Papain-like protease (PLpro) inhibitory effects of cinnamic amides from Tribulus terrestris fruits. Biol Pharm Bull. 2014;37(6):1021-8.

18. Trott O, Olson AJ. AutoDock Vina: improving the speed and accuracy of docking with a new scoring function, efficient optimization, and multithreading. J Comput Chem. 2010;31(2):455-61.

\section{Publisher's Note}

Springer Nature remains neutral with regard to jurisdictional claims in published maps and institutional affiliations. 